\begin{tabular}{|c|c|c|c|}
\hline Article Info & RESEARCH ARTICLE & ARAŞTIRMA MAKALESİ & \\
\hline Title of Article & \multicolumn{2}{|c|}{$\begin{array}{l}\text { SITES Certification System in Landscape } \\
\text { Planning }\end{array}$} & \\
\hline $\begin{array}{l}\text { Corresponding } \\
\text { Author }\end{array}$ & \multicolumn{2}{|c|}{$\begin{array}{l}\text { Pınar ÖZYILMAZ KÜÇÜKYAĞCI } \\
\text { Gebze Teknik Üniversitesi, Mimarlık Fakültesi, Şehir ve Bölge Planlama Bölümü } \\
\text { pozyilmaz@gtu.edu.tr }\end{array}$} & \\
\hline $\begin{array}{l}\text { Received Date } \\
\text { Accepted Date }\end{array}$ & \multicolumn{2}{|l|}{$\begin{array}{l}17.07 .2020 \\
02.10 .2020 \\
\end{array}$} & \\
\hline Author / Authors & Pınar ÖZYILMAZ KÜÇÜKYAĞCI & ORCID: 0000-0002-7045-7722 & \\
\hline How to Cite & \multicolumn{2}{|c|}{$\begin{array}{l}\text { Özyılmaz Küçükyağcı, P. (2020). Peyzaj Alanları Planlamasında SITES Sertifikasyon } \\
\text { Sistemi, Kent Akademisi, Volume, 13, Issue 3, Pages, 475-486 }\end{array}$} & $\begin{array}{l}\text { Kent Akademisi } \\
\text { Urban Academy }\end{array}$ \\
\hline
\end{tabular}

\title{
Peyzaj Alanları Planlamasında SITES Sertifikasyon Sistemi
}

\begin{abstract}
:
There are many certification systems developed to support sustainable spatial development. These systems have been developed to direct the planning and design processes of the environments for different scales, determine the effects of these areas on the environment and reduce their negative consequences. One of these rating systems is SITES (Sustainable SITES Initiative) which is a system that tests the sustainable design and planning processes of landscape areas. As a system that focuses on the landscape issue and evaluates landscape areas in different scales including public open spaces such as streets, squares, green spaces, park areas. It contributes to the management of this process by focusing on the effects of the planned environment on the ecological system. It makes a classification by evaluating the landscape areas with 10 determined topics. In this context, this research discusses the impact of the SITES certification system on landscape areas. In the research, the examples of certified landscape areas with original functions and characteristics are evaluated then the certification processes of these areas are examined. Issues that come to the fore for landscape areas are discussed. According to the assessment, when SITES is used to create sustainable landscaping areas, more environmental, economic, and social issues can be reviewed and more effective areas can be created in a process.
\end{abstract}

KEYWORDS: landscape planning, landscape areas, SITES, certification systems

\footnotetext{
${ }^{1}$ Gebze Teknik Üniversitesi, Mimarlık Fakültesi, Şehir ve Bölge Planlama Bölümü, pozyilmaz@gtu.edu.tr
} 


\section{ÖZ:}

Sürdürülebilir mekânsal gelişimi desteklemek amacıyla geliştirilen çok sayıda sertifikasyon sistemi bulunmaktadır. $\mathrm{Bu}$ sistemler yapı ölçeğinden farklı büyüklükteki ölçeklerde yer alan çevrelerin planlama ve tasarım süreçlerini yönlendirmek, bu alanların çevre üzerinde yaratacağı etkileri belirleyerek olumsuz sonuçlarını azaltmak üzere geliştirilmiştir. Bu derecelendirme sistemlerinden biri olan SITES (Sustainable SITES Initiative) peyzaj alanlarının sürdürülebilir tasarım ve planlama süreçlerini değerlendiren bir sistemdir. Sokak, meydan gibi kamusal açık alanlar gibi farklı ölçekteki peyzaj alanlarını da değerlendiren bir sistem olarak, planlanan çevrenin ekolojik sistemin üzerindeki etkilerine odaklanmakta ve bu sürecin yönetilmesine katkı sağlamaktadır. Peyzaj alanlarını belirlenen 10 konu başlığı üzerinden değerlendirerek bir sınıflandırma yapmaktadır. Bu bağlamda, bu araştırmanın amacı, SITES sertifika sisteminin peyzaj alanları üzerindeki etkisini tartışmaktır. Araştırmada yöntem olarak bu sertifika sistemine dâhil olan farklı fonksiyon ve özgün değer taşıyan peyzaj alanlarına ilişkin örnekler değerlendirilerek, bu alanların sertifikasyon süreçleri incelenmiş, peyzaj alanları için hangi konuların ön plana çıktığı değerlendirilerek SITES sisteminin sürdürülebilir peyzaj alanları yaratmadaki rolü tartışılmıştır.

ANAHTAR KELIMELER: peyzaj planlama, peyzaj alanları, SITES, sertifikasyon sistemleri

\section{GíRIS}

Günümüzde dünyadaki nüfusun artışı sonucunda yaşanan hızlı kentleşme ve gelişmelerin yaşanması ile beraber doğal kaynakların azalması, iklim değişikliği, sera gazları salınımının artması gibi çok sayıda çevresel sorun birçok problemi de beraberinde getirmiştir. Bu sorunların çevre üzerindeki olumsuz etkilerini indirgemek ve bu sorunları ortadan kaldırmak için çözüm olarak birçok farklı ülke ve kurum, farklı konular ve ölçeklere odaklanarak sürdürülebilirlik adına çevrenin daha iyi planlaması ve tasarlanması için sertifikasyon ve derecelendirme sistemleri geliştirmiş̧ir (Reed, Bilos, Wilkinson, \& Schulte, 2009). Geliştirilen bu sistemler, özellikle olumsuz çevresel etkilerin objektif ve somut olarak ortaya konmasında önemli hale gelmiştir (Sev \& Canbay, 2009). Bu sistemler, çevresel sorunlara dikkat çekmekte, farklı sektörlerin çevre üzerindeki yıkıcı etkilerini önlemede de önemli adımlar atılmasını sağlamaktadır. Bu sistemler ile enerji kullanımı, Co2 salınımını, su kullanımı, katı atık gibi parametrelere ilişkin değerlerin düştüğü görülmektedir (Turner \& Frankel, 2008, Kats, 2003, PBS, 2008)

İngiltere'de, 1990 yılında Yapı Araştırma Kurumu (BRE) tarafından ortaya konan Yapı Araştırma Kurumu Çevresel Değerlendirme Metodu olan BREEAM bu sertifika programlarının ilkidir. Bu metodu LEED (ABD), SBTool (Uluslararası), EcoProfile (Norveç), PromisE (Finlandiya), Green Mark for Buildings (Singapur), HK-BEAM ve CEPAS (Hong Kong), Green Star (Avustralya), SBAT (Güney Africa), CASBEE (Japonya) ve Environmental Status (İşveç) gibi çok sayıda metot izlemiştir (Sev \& Canbay, 2009). Bu sistemlerde enerji, ulaşım, sağlık, refah, alan kullanımı, kirlilik, su kullanımı gibi çok sayıda konuda çevresel parametreler tanımlanarak yapıların ya da alanların değerlendirilmesi yapılmaktadır. Amaç, sürdürülebilir çevreler yaratarak çevreye verilen zararı en aza indirgemektir.

\section{SITES (Sustainable Sites Initiative) Değerlendirme Sistemi}

Derecelendirme sistemlerinden biri olan SITES (Sustainable SITES Initiative) peyzaj alanlarının sürdürülebilir tasarım ve planlama süreçlerini değerlendiren bir sistem olarak başta ekosistem servislerini koruma, geliştirme ve yenileme amacıyla ortaya çıkmıştır. SITES'ın 2009 yılında yayınlanan raporuna göre, doğal yaşam sistemleri ve uygulama sürecindeki yapım sistemlerini birlikte düşünerek tasarım, yapım, inşaat, uygulama ve bakım çalışmalarında "gelecek nesillerin ihtiyaçlarını riske atmadan günümüz ihtiyaçlarına cevap vermek" hedeflenmiştir (USGBC, 2009). SITES, su, toprak, hava, bitki örtüsü gibi çevrenin tüm bileşenlerini göz önüne alarak, mevcut kaynaklara zarar vermeden çevresel değeri arttıracak; zarar gören ekosistem servislerini yenileyerek koruma kullanma dengesini gözetecek bir yaklaşımla insan sağlığını da düşünerek planlama ve tasarım süreçlerinin yönetilmesi yönünde ilkeler ortaya koymuştur (USGBC, 2009) (Tablo 1). Peyzaj konusuna odaklanarak sokak, meydan gibi kamusal açık alanları da kapsayan farklı ölçekteki peyzaj alanlarını değerlendiren bir sistem olarak, planlanan çevrenin ekolojik sistemin üzerindeki etkileri bağlamında bu sürecin yönetilmesine katkı sağlama amacını taşımaktadır. Bu amacı taşırken sistem konuyla ilgili tüm paydaşları ilgilendiren bir şekilde yönergeler içermektedir. Mülkiyet hakkına sahip olan kişilerden, yöneticilere, plancılardan, peyzaj mimarları, mimar ve mühendislere kadar tüm ilgili gruplara ekosistem servislerini koruma, yenileme ve geliştirme bağlamında çevre korunurken aynı zamanda nasıl geliştirileceği konusunda da fayda sağlamaktadır. Bu kapsamda bu disiplinler arası sistemin geliştirilmesinde ASLA (the American Society of Landscape 
Architect), Lady Bird Johnson Wildflower Center at the University of Texas at Austin ve United States Botanic Garden gibi farklı kurum ve kuruluşlar öncülük etmiştir (Sustainable Sites Initiative, 2014).

Tablo 1. SITES ilkeleri (USBGC, 2008; USBGC, 2009)

\begin{tabular}{|c|c|}
\hline İLKELER & \\
\hline Zarar vermemek & $\begin{array}{l}\text { - Çevrenin değerini düşürecek değişiklik yapmamak } \\
\text { - Sürdürülebilir tasarımda ekosistem servislerinin yenilenmesi için alanın } \\
\text { önceki durumu ve gelişimi firsat olarak değerlendiren projeleri } \\
\text { desteklemek }\end{array}$ \\
\hline Önemli ilke & $\begin{array}{l}\text { - İnsan ve çevre sağliğı için risk oluşturabilecek kararlar almamak, bazı } \\
\text { kararlar geri dönüşü olmayan zararlar verebilir. Bu sebeple bütün } \\
\text { alternatifler değerlendirilmeli }\end{array}$ \\
\hline $\begin{array}{l}\text { Doğa ve kültürle tasarım } \\
\text { yapmak }\end{array}$ & $\begin{array}{l}\text { - Ekonomik, çevresel ve kültürel koşullara uygun, yerel, bölgesel ve global } \\
\text { ölçeği düşünerek tasarım yaratmak ve uygulamak }\end{array}$ \\
\hline $\begin{array}{l}\text { Koruma ve yenileme } \\
\text { hiyerarşisi içinde karar } \\
\text { almak }\end{array}$ & $\begin{array}{l}\text { - Sürdürülebilirlik ilkesi doğrultusunda mevcut çevresel özellikleri ve } \\
\text { kaynakları koruyarak ve kaybolan ya da zarar görmüş ekosistem } \\
\text { servislerini yenileyerek ekosistem servislerinin yararlarını maksimize } \\
\text { etmek ve benzer koşullar sağlamak }\end{array}$ \\
\hline $\begin{array}{l}\text { Yenilenebilir sistemler } \\
\text { sağlamak }\end{array}$ & $\begin{array}{l}\text { - Yenilenebilir sistemler tarafından sağlanan sürdürülebilir çevre ile } \\
\text { gelecek nesillerin ihtiyacını karşılamak. }\end{array}$ \\
\hline Yaşayan bir proses sağlamak & $\begin{array}{l}\text { - Varsayımları ve değerleri devamlı olarak yeniden değerlendirmek ve } \\
\text { demografik ve çevresel değişime ayak uydurmak }\end{array}$ \\
\hline $\begin{array}{l}\text { Bir düşünce sistemi yaklaşım } \\
\text { kullanmak }\end{array}$ & $\begin{array}{l}\text { - } \quad \text { Ekosistem içindeki ilişkileri anlamak ve değerlendirmek, ekosistem } \\
\text { servislerinin sürdürebilirliğini sağlayan ve yansıtan bir yaklaşım } \\
\text { kullanmak, doğal süreç ve insan aktiviteleri arasındaki bütünleyici ve } \\
\text { önemli ilişkiyi yeniden kurgulamak }\end{array}$ \\
\hline $\begin{array}{l}\text { İşbirliğine açık ve etik bir } \\
\text { yaklaşım kullanmak }\end{array}$ & $\begin{array}{l}\text { - Uzun dönemli sürdürülebilirlikle bağlantılı olarak uzmanlar, müşteriler, } \\
\text { üretici ve kullanıcılar arasında direkt ve açık bir iletişim kurmak }\end{array}$ \\
\hline Entegrasyonu sürdürmek & $\begin{array}{l}\text { - Şeffaf ve katılımcı bir liderlik uygulamak, teknik bir şekilde araştırma } \\
\text { yapmak, yeni bulgularla net, tutarlı ve zamanında ilişki kurmak }\end{array}$ \\
\hline $\begin{array}{l}\text { Çevresel yönetimi teşvik } \\
\text { etmek }\end{array}$ & $\begin{array}{l}\text { - Alan gelişimi ve yönetimi bütününde çevresel yönetimi desteklemek- } \\
\text { günümüz ve gelecek nesiller için sağlıklı ekosistemlerin yönetimi ile } \\
\text { yaşam kalitesini geliştirmek }\end{array}$ \\
\hline
\end{tabular}

2007'den bu yana SITES, yönergelerini ve performans kriterlerini içeren üç farklı rapor yayınlamıştır. 2009 yılında yayınlanan raporda, 160'dan fazla proje alanı üzerinde yapılan pilot çalışmalara ait değerlendirme sonuçları yer almış, bu sonuçlara göre kriterler ve yönergeler düzenlenmiştir (Sustainable Sites Initiative, 2014). Bu sistemde belirli bir alanın değerlendirmesi yapılırken bir puanlama ve önkoşul matrisi kullanılmaktadır. Bu puanlama tablosunda değerlendirilen alan için her bir krediye tahsis edilen değer, belirlenen dört hedef ve alt kriterleri bağlamında oluşmaktadır (Tablo 2.). Bu hedefler toprak, su, hava gibi çevrenin tüm bileşenlerini korumak, zarar gören bir sistem varsa onarmak, problem yaratan bir durumu ortadan kaldırmak, sürdürülebilirliği çevresel, sosyal ve ekonomik olarak her boyutuyla değerlendirerek bir proje yaratmayı amaçlamaktadır.

Tablo 2. SITES'ın öngördüğü hedefler (Sustainable Sites Initiative, 2014).

TEMEL HEDEFLER ALT PARAMETRELER

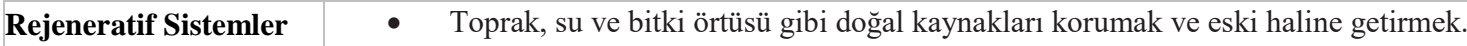

Yaratmak ve

- Biyoçeşitliliği arttırmak

Dayanıklıığı Artırmak • - Havayı ve suyu temizlemek gibi çoklu ekosistem hizmetleri sağlamak için peyzajı 


\begin{tabular}{|c|c|}
\hline & $\begin{array}{l}\text { geliştirmek, } \\
\text { - } \quad \text { Habitatı ihtiyaçlarını karşılamak ve karbon depolamak. } \\
\text { - } \quad \text { Gelişen tehlikeleri ve doğal afetleri azaltmak. } \\
\text { Izlemek ve uyarlanabilir yönetim için planlama yapmak }\end{array}$ \\
\hline $\begin{array}{l}\text { Gelecekteki Kaynak } \\
\text { Arzını Sağlamak ve } \\
\text { İklim Değişikliğini } \\
\text { Azaltmak }\end{array}$ & $\begin{array}{l}\text { - } \quad \text { Enerji tüketimini en aza indirmek ve düşük karbonlu ve yenilenebilir enerji kaynaklarının } \\
\text { kullanımını teşvik etmek } \\
\text { - Sera gazı emisyonlarını, ağır metalleri, kimyasalları ve diğer kirleticileri en aza indirmek } \\
\text { veya ortadan kaldırmak } \\
\text { - } \quad \text { Malzemeleri ve kaynakları azaltmak, yeniden kullanmak, geri dönüştürmek } \\
\text { - Su tasarrufu sağlamak. } \\
\text { Yeniden bitki örtüsü ile karbon alıcı kapasitesini arttırmak }\end{array}$ \\
\hline $\begin{array}{l}\text { Tasarım, Geliştirme ve } \\
\text { Bakım Uygulamalarla } \\
\text { Piyasayı Dönüştürmek }\end{array}$ & $\begin{array}{l}\text { - } \quad \text { Sanayi ve profesyonel uygulamada liderlik etmek. } \\
\text { - } \quad \text { Sistemli düşünme, bütünleştirici ve işbirlikçi bir tasarım yaklaşımı kullanmak. } \\
\text { - Tasarım süreci hakkında bilgi edinmek için yaşam döngüsü analizlerini kullanmak. } \\
\text { Yerel ekonomileri ve sürdürülebilirlik politikalarını desteklemek. }\end{array}$ \\
\hline $\begin{array}{l}\text { İnsan Refahını } \\
\text { Arttırmak ve Toplumu } \\
\text { Güçlendirmek }\end{array}$ & $\begin{array}{l}\text { - İnsanları doğaya yeniden bağlamak } \\
\text { - } \quad \text { İnsan sağlığını (fiziksel, zihinsel ve ruhsal) iyileştirmek. } \\
\text { - } \quad \text { Doğal sistemlerin anlaşılmasını teşvik eden eğitim sağlayarak bu yönde yöneticiliği teşvik } \\
\text { etmek ve peyzajın değerini bilmek } \\
\text { - } \quad \text { Kültürel bütünlüğü ve bölgesel kimliği teşvik etmek. } \\
\text { - Toplumun katılımı ve savunuculuğu için firsatlar sağlamak. }\end{array}$ \\
\hline
\end{tabular}

$\mathrm{Bu}$ sistemde farklı ölçek ve farklı fonksiyonlarda peyzaj alanları değerlendirilebilmektedir. Yeni gelişen alanlar yanında mevcut durumunda önemli değişiklikler yapılan alanlarda kapsama dâhil edilebilmektedir. Minimum büyüklüğü $185,8 \mathrm{~m}^{2}$ olan alanlardan itibaren maksimum büyüklükle ilgili bir sınır bulunmamaktadır. Değerlendirilen alanlar, kentsel, kırsal ya da farklı bir formasyonda olabilmektedir. Alan üzerinde bina olup olmaması değerlendirme sisteminin durumunu etkilememektedir (Sustainable Sites Initiative, 2014). Değerlendirilen alanlar;

- Açık alanlar - yerel, eyalet ve milli parklar; Botanik bahçeler, arboretumlar

- Sokaklar ve plazalar

- Ticari alanlar - perakende ve ofis alanlar1; kurumsal kampüsler

- Konut alanları - mahalleler veya bireysel bahçeler

- Eğitim alanları/ Kurumsal alanlar — kamu ve özel kampüsler; müzeler, hastaneler

- Altyapiya ait alanlar

- İdari alanlar

- Askeri alanlar

- Sanayi alanları olabilmektedir.

\subsection{SITES Sertifikasyon Sisteminin Kriterleri}

18 önkoşulu bulunan sistemde alandaki sürdürülebilirliği değerlendirmek için 10 başlık altında 48 kriter için toplamda 200 puan karşıllı̆ı bulunmakta, 4 farklı derece ile sertifikalar kademelenmektedir (Sustainable Sites Initiative, 2014). (Tablo 3.)

Tablo 3. SITES sertifika dereceleri 


\begin{tabular}{|c|c|c|c|}
\hline \multicolumn{5}{|c|}{ SITES Sertifikası dereceleri ve puanlar1 } \\
\hline Sertifikalı & Gümüş & Altın & Platin \\
\hline $70-84$ puan & $85-99$ & $100-134$ & 135 puan \\
\hline
\end{tabular}

SITES'da önkoşullar ve kriterler projelerin başlangıcından itibaren göz önünde bulundurularak 10 başlık altında incelenmektedir: Saha Koşulları (Area Context), Tasarım öncesi Değerlendirme ve Planlama (Pre-Design Assessment and Planning), Mekân tasarımı: Su (Site Design-Water), Mekân tasarımı Toprak ve Bitki Örtüsü (Site Design-Soil and Vegetation), Mekân tasarımı Malzeme Seçimi (Site Design-Materials Selection, Mekân tasarımı: Halk Sağllğı ve Refah Düzeyi (Site Design-Human Health and Well-Being), Inşaat Aşaması (Construction), İșletme ve Bakım (Operations and Maintenance), Eğitim ve Performans Ölçümü (Education - Performance Monitoring), İzleme ve İnovasyon Süreci (Monitoring and Innovation) (Sustainable Sites Initiative, 2014). Belirlenen bu konular üzerinden proje bir değerlendirmeye tabi tutulmaktadır. Bir projenin değerlendirilebilmesi için ön koşullar temel performansı ifade ettiğinden tüm ön koşulları karşılaması beklenmektedir. Projenin, kapsamlı bir planı ve entegre bir proje takımı olması önemlidir. Planlama, tasarım, inşaat, işletme ve bakım için projenin kararları gözden geçirilmektedir. SITES, bir yol haritası oluşturmakta, değerlendirmeyi bu yol haritası üzerinden yürütmektedir. Alanın kendine özgü koşullarını destekleyerek, yeni bir çevre yaratırken, uygun, işlevsel ve kullanım amacına uygun olarak çevreye uyumlu olmasinı desteklemektedir (Tablo 4.).

- Saha Koşulları

Bir projenin kendine özgü koşullarını göz önüne alarak, hassasiyet gösterilmesi gereken alanların korunmasına yönelik planlamanın yapılmasını öngörmektedir. Alanın mevcut durumunda var olan çevresel, sosyal, fiziksel tüm nitelikleri göz önüne alarak zarar gören bir sistem varsa onarmay1, varsa problem yaşanan bir konuya çözüm getirmeyi bir yaklaşım olarak tarifleyen sistem alanın bu şekilde planlanmasını beklemektedir.

- Tasarım Öncesi Değerlendirme ve Planlama

Tasarıma başlamadan önce bir tasarım ekibi, saha koşullarının değerlendirildiği kapsamlı bir envanter çalışması gerekmektedir. Ayrıca alana ilişkin tüm paydaşların birlikteliği ile katılımcı ve disiplinler arası bir planlama anlayışı beklenmektedir.

- Mekân Tasarımı: Su

Alanın mevcut su varlığı üzerine yapılan bir değerlendirmeyi kapsamaktadır. Mevcut suyun korunması, yağış miktarına bağlı bir yönetim planının yapılması, yağmur suyu kullanımının desteklenmesi, su kullanımının etkin yapılması, su ekosistemi varsa bunun devamlılığının sağlanması gibi daha birçok konunun projede desteklenmesi beklenmektedir.

- Mekân Tasarımı: Toprak ve Bitki Örtüsü

Alan için; toprağın etkin kullanımı ve buna bağlı mevcut bitki örtüsünün korunması beklenmektedir. Toprağın verimini arttırmak, uygun bitki türü seçimi yapmak, yerel bitki türlerine önem vermek gibi konular yer almaktadır. Isı adası etkisini azaltmak, bitkilendirme yoluyla yapıların enerji kullanımı azaltmak gibi yaklaşımlar desteklenmektedir.

- Mekân Tasarımı: Malzeme Seçimi

Ön koşul olarak, ahşap kullanımının tehdit altındaki ağaç türlerinden yapılmamasını destekleyen sistemde, geri dönüşümlü malzeme kullanımı, bölgesel ve yerel malzemelerin tercih edilmesi, insan sağlı̆ğ ve çevre üzerine etkilerini en aza indiren malzemelerin kullanılmasını sağlamak gibi koşullar yer almaktadır.

- Mekân Tasarımı 
Halk Sağlığı ve Refahı: Kültürel ve tarihi alanların korunmasını desteklemektedir. Alanın erişilebilir, güvenli, eşitlikçi, demokratik, her kesime uygun olmasını, kullanıcının fiziksel, zihinsel ve sosyal ihtiyaçlarını karşılanmasını, ekonomik olarak da alanda tüketimin azaltılarak üretimin öne çıkmasını hedeflemektedir.

- İnşaat Aşaması

Sürdürülebilir inşaat uygulamaları kullanarak, kirleticilerin kontrolü, bozulmuş toprağın yeniden kazanılması, atık malzemenin yeniden değerlendirilmesi gibi inşaat aşamasındaki çok farklı konuyu süreç içerisinde göz önünde bulundurulmasını desteklemektedir.

- İșletme ve Bakım

Bir alanın işletmesi ve bakımı sırasında enerji tüketimi, atık yöntemi gibi konulara dikkat çekilmektedir. Enerjinin etkin kullanımı, hava, su, toprak kalitesini etkileyecek uygulamalardan uzak durmayı önemseyen bir planlama çerçevesinde alanın işletmesinin ve bakımının yapılmasını desteklemektedir.

- Eğitim ve Performans Ölçümü

Sürdürülebilirlik konusundaki bilincin kullanıcıya aktarılmasını destekleyen bir süreç önermektedir. Ayrıca alanın performansının izlenmesi ve raporlanmasının, sorunların fark edilmesini sağlayacağından bu raporlama sürecinin alana pozitif yönlü etkisi olacağı, iyileştirme yönlü çalışmaları destekleyeceği öngörülmektedir.

- İnovasyon veya Örnek Performans

$\mathrm{Bu}$ aşama proje alanına ilâve bir kredi sağlamaktadır. Bu konular veya dışındaki konulara ilişkin yenilikçi yaklaşımlar, yararı olan yeni plan ve programlar önermek ve uygulamak sistem açısından desteklenmektedir.

Bu konular sürdürülebilir bir peyzaj alanı yaratmak için değerlendirilmektedir. Bu kapsamda bir sistem oluşturulmuş, kriterler belirlenerek alanın bu kriterler bağlamında belirlenen kredilerden yüksek puan toplaması hedeflenmiştir. Bu sistem çok sayıda konuyu detaylı, ayrıntılı bir şekilde tanımlamış, böylelikle bir kontrol listesi oluşturulmuştur. Günümüzde sürdürülebilir yeşil alan planlaması başlığı altında yapılan çok sayıda uygulama kimi zaman bu konular göz önünde bulundurulmadan yapılmaktadır. Bu sebeple bu kapsamlı ve geliştirilmeye açık sistemin bir peyzaj planını değerlemede avantaj ve kolaylık sağladığı ve sağlayabileceği görülmektedir.

Tablo 4. SITES Skor Tablosu (Sustainable Sites Initiative, 2014). 


\section{SITES v2 Skor Tablosu Özeti}

EVET ? HAYIR

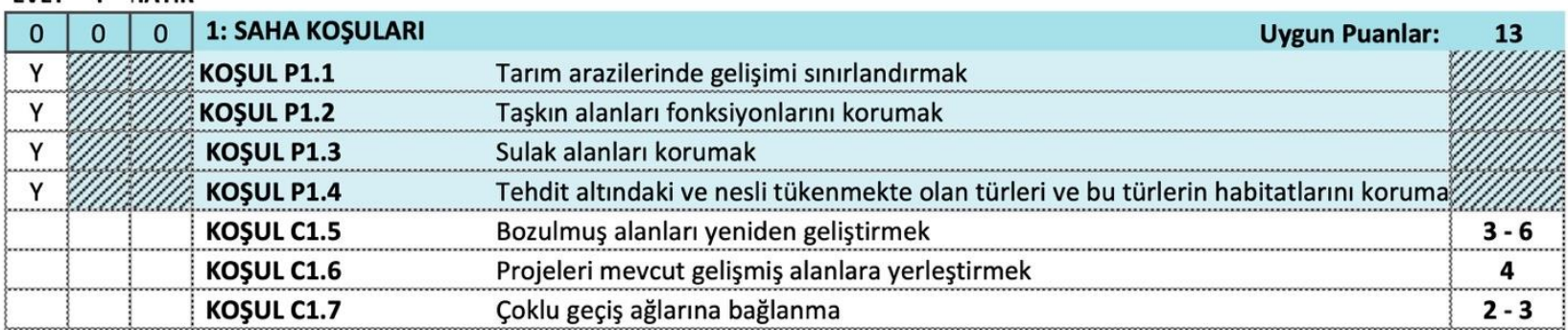

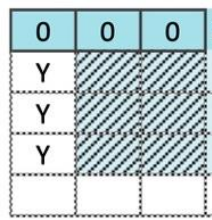

2:TASARIM ÖNCESI DEĞERLENDIRME VE PLANLAMA

TASARIM ÖNCESI P2.1 Entergre olabilecek bir tasarım süreci kullanmak

TASARIM ÖNCESI P2.2 Tasarım öncesi bir saha değerlendirmesi yapmak

TASARIM ÖNCESI P2.3 VSPZ'leri belirlemek ve iletişim kurmak

TASARIM ÖNCESI C2.4 Tüm kullanıcı ve paydaşlarla bağlantı kurmak

\begin{tabular}{|c|c|c|c|c|c|c|}
\hline 0 & 0 & 0 & \multicolumn{2}{|c|}{ 3: MEKÂN TASARIMI - SU } & \multirow[t]{2}{*}{ Uygun Puanlar: } & \multirow[t]{2}{*}{23} \\
\hline$Y$ & $\mathbb{Z Z}$ & $/ 2$ & SU P3.1 & Sahada yağışları kontrol etmek ve yönetmek & & \\
\hline$Y$ & \# & & SU P3.2 & Peyzaj sulamada su kullanımını azaltmak & & \\
\hline & & & SU C3.3 & Yağışları taban suyu çizgisinde yönetmek. & & $4-6$ \\
\hline & & & SU C3.4 & Dış mekân su kullanımını azaltmak & & $4-6$ \\
\hline & & & SU C3.5 & Yağmur suyunu fayda sağlayacak şekilde kullanmak & & $4-5$ \\
\hline & & & SU C3.6 & Sudaki ekosistemleri yeniden oluşturmak & & 4- 6 \\
\hline
\end{tabular}

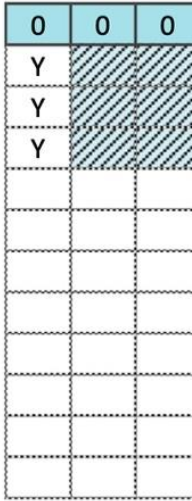

4: MEKÂN TASARIMI - TOPRAK VE BITKI ÖRTÜSÜ

TOPRAK+BÖ P4.1 Bir toprak yönetim planı oluşturmak ve buna bağlı kalmak.

Uygun Puanlar: TOPRAK+BÖ P4.2 İstilacı bitkileri kontrol etmek ve yönetmek TOPRAK+BÖ P4.3 Uygun bitki türlerini kullanmak TOPRAK+BÖ C4.4 Sağlıklı toprakları ve uygun bitki örtüsünü korumak Özel statüdeki bitki örtüsünü korumak TOPRAK+BÖ C4.6 Yerel bitkileri korumak ve kullanmak TOPRAK+BÖ C4.7 Yerel bitki topluluklarını korumak ve yeniden oluşturmak. TOPRAK+BÖ C4.8 Biyokütleyi optimize etmek TOPRAK+BÖ C4.9 Kentsel ISI adası etkilerini azaltmak TOPRAK+BÖ C4.10 Bina enerji kullanımını en aza indirmek için bitki örtüsünü kullanmak. TOPRAK+BÖ C4.11 Felaket getiren orman yangını riskini azaltmak.

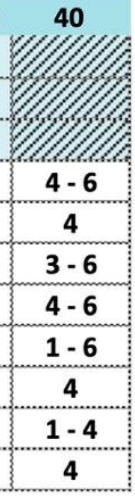

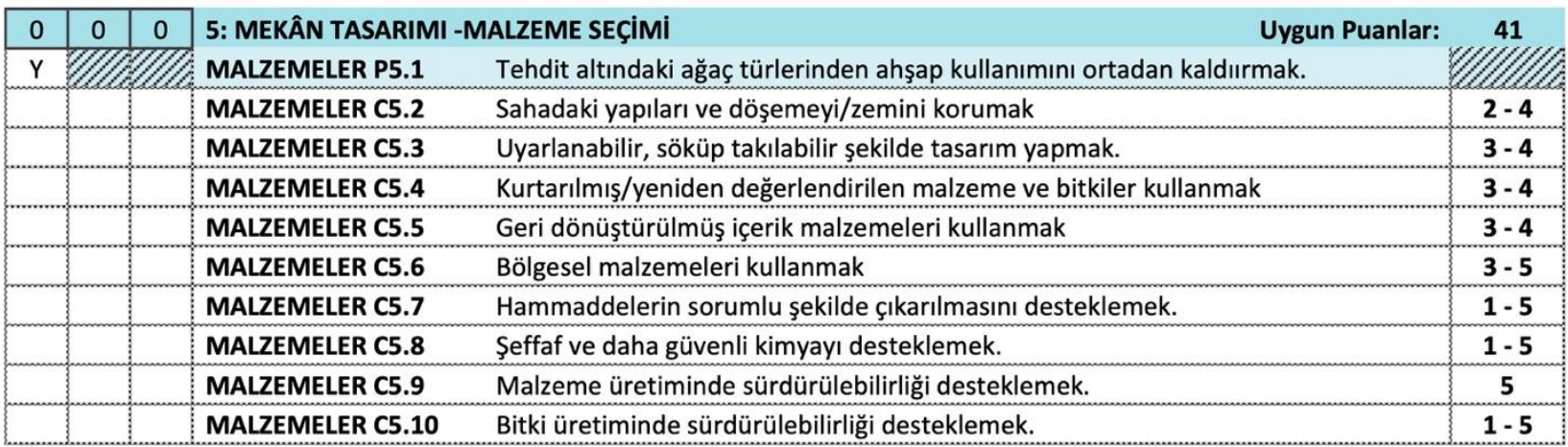

Tablo 4 (Devam). SITES Skor Tablosu (Sustainable Sites Initiative, 2014).

SITES Certification System in Landscape Planning 
EVET ? HAYIR

\begin{tabular}{|c|c|c|c|c|c|}
\hline 0 & 0 & 0 & \multicolumn{2}{|c|}{ 6: MEKÂN TASARIMI -HALK SAĞLIĞI VE REFAH DÜZEYi } & 30 \\
\hline & & & HSRD C6.1 & Kültürel ve tarihi yerleri korumak ve bunu sürdürmek & $2-3$ \\
\hline & & & HSRD C6.2 & Sahada optimum erişilebilirlik, güvenlik ve yol bulmayı sağlamak. & 2 \\
\hline & & & HSRD C6.3 & Sahayı eşitlikçi kullanımı teşvik etmek & 2 \\
\hline & & & HSRD C6.4 & Zihinsel yenilenmeyi desteklemek & 2 \\
\hline & & & HSRD C6.5 & Fiziksel aktiviteyi desteklemek & 2 \\
\hline & & & HSRD C6.6 & Sosyal bağlantıyı desteklemek & 2 \\
\hline & & & HSRD C6.7 & Yerinde gıda üretimi sağlamak & $3-4$ \\
\hline & & & HSRD C6.8 & Işıı kirliliğini azaltmak & 4 \\
\hline & & & HSRD C6.9 & Yakıt tasarruflu ve çok modlu taşımayı teşvik etmek & 4 \\
\hline & & & HSRD C6.10 & Çevresel tütün dumanına maruziyeti en aza indirgemek & $1-2$ \\
\hline & & & HSRD C6.11 & Yerel ekonomiyi desteklemek & 3 \\
\hline
\end{tabular}

\begin{tabular}{|c|c|c|c|c|c|}
\hline 0 & 0 & 0 & 7: INŞAAT AŞAMASI & Uygun Puanlar: & 17 \\
\hline$Y$ & & & INŞAAT P7.1 & Sürdürülebilir inşaat uygulamalarını bilmek ve uygulamak & \\
\hline Y & & & INSSAAT P7.2 & İnşaat kirleticilerini kontrol etme ve tutmak & \\
\hline Y & $\mathbb{Z}$ & & INŞAAT P7.3 & İnşaat sırasında bozulmuş toprakları geri kazanmak & \\
\hline & & & INSSAAT C7.4 & Önceki gelişimden rahatsız toprakları yeniden kullanmak & $3-5$ \\
\hline & & & INSSAAT C7.5 & İnşaat ve yıkım malzemelerini yenidendeğerlendirmek & $3-4$ \\
\hline & & & INŞAAT C7.6 & Yeniden kullanılabilir bitki örtüsünü, kayaları ve toprağı değerlendirmek & $3-4$ \\
\hline & & & INŞAAT C7.7 & İnşaat sırasında hava kalitesini korumak & $2-4$ \\
\hline
\end{tabular}

\begin{tabular}{|c|c|c|c|c|c|}
\hline 0 & 0 & 0 & 8. IŞLETME VE BAKIM & Uygun Puanlar: & 22 \\
\hline $\mathrm{Y}$ & & $\mathbb{Z Z}$ & I+B P8.1 & Sürdürülebilir saha bakımını planlamak & \\
\hline $\mathrm{Y}$ & $1 / 1$ & $\mathbb{Z}$ & İ+B P8.2 & Geri dönüştürülebilir ürünlerin depolanması ve toplanması sağlamak & \\
\hline & & & İ+B C8.3 & Organik maddeleri geri dönüştürmek & $3-5$ \\
\hline & & & İ+B C8.4 & Pestisit ve gübre kullanımını en aza indirmek & $4-5$ \\
\hline & & & İ+B C8.5 & Dış mekan enerji tüketimini azaltmak & $2-4$ \\
\hline & & & İ+B C8.6 & Peyzaj alanlarının elektrik ihtiyaçları için yenilenebilir kaynaklar kullanmak & $3-4$ \\
\hline & & & í+B C8.7 & Peyzaj bakımı sırasında hava kalitesini korumak & $2-4$ \\
\hline
\end{tabular}

\begin{tabular}{|c|c|c|c|c|c|c|}
\hline 0 & 0 & 0 & \multicolumn{2}{|c|}{ 9. EĞiTIM + PERFORMANS ÖLÇME } & Uygun Puanlar: & 11 \\
\hline & & & EĞiтiM C9.1 & Sürdürülebilirlik bilincini ve eğitimini teşvik etmek & & $3-4$ \\
\hline & & & EĞiTiM C9.2 & Bir vaka çalışması geliştirin ve ilişkilendirmek & & 3 \\
\hline & & & EĞіTIM C9.3 & Saha performansını izlemeyi ve raporlamayı planlamak & & 4 \\
\hline
\end{tabular}

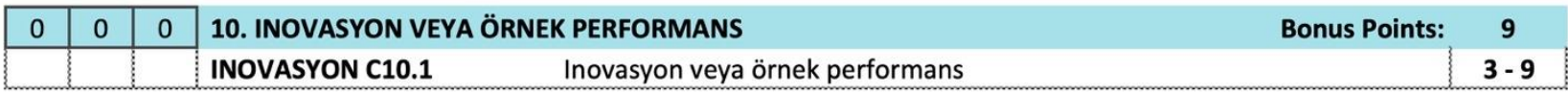

EVET ? HAYIR

KEY

EVET Proje güvenilir puana ulaşılabilir

? \% 100 emin değil, puan elde etmek için çalışmalı

HAYıR Proje bu kredi puanlarına ulaşamıyor
SITES Sertifikasyon seviyeleri Puanlar

\begin{tabular}{|c|c|}
\hline SERTIFIKALI & 70 \\
\hline GÜMÜS & 85 \\
\hline ALTIN & 100 \\
\hline PLATINYUM & 135 \\
\hline
\end{tabular}

\section{SITES Tarafından Sertifikalandırılmış Peyzaj Alanlarına İlişkin Değerlendirme}

SITES Certification System in Landscape Planning

Journal of Urban Academy | Volume: 13 Issue: 3 | ISSN: 2146-9229 
SITES sistemi çok sayıda peyzaj alanına ait projeyi sertifikalandırmışıtır. Bu kapsamda, farklı ülkelerde kent içinde, dışında ve banliyölerde yer alan açık alanlar, parklar, bahçeler, endüstriyel tesis alanları, eğitim tesis alanları, kampüs alanları, rekreasyon alanları, sokaklar, meydanlar, doğa koruma alanları, çatı bahçeleri, arboretumlar gibi çok sayıda proje incelenmiştir (SITES,2014). İncelenen sertifikalı peyzaj alanları değerlendirildiğinde şu sonuçlar elde edilmiştir;

-Bu sisteme dâhil olan peyzaj alanlarının enerji, su, toprak, bitki örtüsü gibi pek çok farklı konularda kazanımlar elde ettiği görülmüştür.

-Projelerde daha yeşil, daha sürdürülebilir, daha enerji etkin bir çevre yaratmak için farklı ve yenilikçi uygulamalar geliştirilmiştir.

-Tasarım ve planlama ekiplerine yol gösteren bir sistem olduğundan tasarım ve planlama amaçlarını yönlendirmiştir.

-Alanın kendine özgü ekosistemi, -örneğin sulak alan olması gibi- değerlendirilerek alanda yer alacak fonksiyonlar (kuş gözlemi vb.) ona göre belirlenmiştir. O alanın kendi habitatına ilişkin envanter oluşturularak, insan-çevre ilişkisi kurulmaya çalışılmıştır.

-Alanların yeşil alan olarak kapladığı alanda ciddi artışlar görülmüştür. Yerel ve mevcut bitki türlerinin kullanımına ağırlık verilmiştir.

-Enerjiyi korumak, enerji üretmek ve daha az enerji kullanmak için farklı projeler geliştirilmiştir. Özellikle güneş enerjisi kullanımı desteklenmiş, enerji tüketimi azaltılmıştır.

-Alınan kararlar sadece alanın dış mekâna ait kısımlarını değil, yapılara ilişkin kararları da etkilemiştir. Örneğin; güneş, toprak, rüzgâr ve bitkiler kullanılarak aydınlatma, ısıtma, soğutma, atık suyu temizleme gibi konular için inovatif çözümler üretilmiştir.

-Zarar gören su varlığının temizlenerek hem flora hem fauna için kullanılması sağlanmış, yağmur suyunun yönetimi önem kazanarak çok çeşitli yağmur suyu yönetim planları oluşturulmuştur. Su kalitesinin iyileştirilmesi sağlanmıştır. Suyun buharlaşma gibi belli parametreleri kontrol altına alınarak tasarruf programları geliştirilmiştir. Yağmur bahçeleri, geçirgen kaldırımlar, yağmur suyu hasadı, yeşil çatı gibi uygulamalar kullanılarak yağmur suyundan maksimum faydalanma sağlanmıştır. Bunun yanında sel riski azaltılmış, yer altı kaynakları korunmuştur.

-Bitki türleri gibi hayvan türleri içinde çeşitli programlar ve düzenlemeler geliştirilerek sayılarının artması ile alan içinde bu türler için yaşam alanları oluşturulmuş, istilacı türlerle mücadele edilmiştir. Bitki türleri seçiminde iklim ve toprak yapısına ilişkin veriler kullanılmıştır. Alanda yer alan mevcut bitkilerin korunmasına önem verilmiştir.

-Yapılan düzenlemeler ile hava, su, toprak kalitesinin arttığı gözlemlenmiştir. Örneğin; karbon emisyonlarının düştüğü görülmüştür.

-Sadece su, toprak, hava kirliliği değil, gürültü kirliliğini yönlendirmek ve azaltmak için de çeşitli düzenlemeler yapılmıştır.

-Alanların tasarımlarının farklılaşması ile kullanıcı için daha güvenli, daha çekici, daha canlı alanlar yaratılmıştır. Bu tasarım ve planlama süreçlerinde kullanıcılar da bu sürece dâhil edilerek katılımcı bir yaklaşım oluşturulmuştur.

- Malzeme kullanımında kırık beton parçaları, geri dönüştürülmüş cam gibi geri dönüştürülmüş malzemelere önem verilerek farklı uygulamalar yapılmıştır. Bunun yanında çoğunlukla yerel malzemeye de önem verilmiştir.

-Ekonomik olarak hizmet maliyetinde tasarruf edilmiştir. Peyzaj bakımı için harcamanın azaltılması için çeşitli tasarruf programları geliştirilmiştir.

-Halk sağlığı ve refah düzeyi adına proje alanlarında alana ilişskin vizyon ve misyonlar oluşturulmuştur. İnsan-çevre etkileşimi proje alanlarına yansıtılarak çeşitli düzenlemeler yapılmıştır. Yalnız kullanıcılar için değil alanda çalışanlar içinde farklı olanaklar ve imkanlar yaratılarak alanın yüksek performanslı bir çalışma ortamı olması sağlanmıştır. 
-"Yavaş yeşil yaklaşımı” gibi farklı kavramlar ve yaklaşımlar geliştirerek alanlar için stratejiler belirlenmiştir.

-İnşaat ve işletme adımlarında sürdürülebilir uygulamalar geliştirilmiştir.

-Kullanıcının zihinsel rehabilitasyonu için de farklı düzenlemeler yapılmıştır. Örneğin; sessiz açık alan yaratmak gibi uygulamalar kullanılmıştır. Yoga, meditatif yürüyüş alanları ve hareketli doğa yürüyüşleri gibi aktiviteler sunan alanlar yaratılmıştır.

-Projeler SITES ilkeleri bağlamında geliştirildiğinde kullanım oranı artmıştır. Alanda aktivite imkanları arttırıldığından rekreasyon desteklenmiştir.

-Sürdürülebilirlik bilincini aşılamak için eğitim programları düzenlenmiştir.

Bu ve benzeri sistemlerin avantajları olduğu gibi dezavantajları da bulunmaktadır.

-Sistemde yer alan koşullar ve kriterlerin bir alanın planlama ve tasarım sürecine yansıması için belli bir maliyet gerekmektedir. Enerji, su, toprak verimliliği için yapılacak uygulamalar gibi birçok düzenleme için belli bir ekonomik güç gerektirmektedir. Bunun yanında bu maliyet içinde sertifikasyon sistemi kuruluşu, yeşil bina danışman firması da bulunmaktadır.

-Bu sistemin ekolojik faydalarını arka plana iterek bir pazarlama aracına dönüşmesi de sistemin farklı bir amaçla kullanıldığını gösterebilmektedir. Sadece alana kullanıcı çekmek ya da alanın popülerliğini artırmak için sisteme dâhil olunarak sistem bu amaçla kullanılabilmektedir.

-Sistemde yer alan konu başlıkları yerelliği desteklese de tüm dünyada geçerli bir değerlendirme dizini farklı niteliklere sahip bölgelerdeki alanları değerlendirmeye çalışmak beraberinde sorunlar getirebilecektir. Her bölgeye uygun olup olamayacağı tartışılmalı, parametreler bazında esnek olması sağlanabilmelidir. Belki de her ülke için yerel, bölgesel, ulusal kriterler belirlenmelidir.

-Süreç, kriterler bağlamında bir yol haritası oluştursa da alan için detaylı ve uzun süren bir çalışmayı gerektirmektedir. Sürecin iyi yönetilmesi, tasarım ve plancı ekibin disiplinler arası çalışma yapması dolayısıyla ekibin farklı uzmanlık alanlarına sahip kişilerden oluşması gerekliliği doğmaktadır.

Genel olarak bu sistem, proje alanlarında sürdürülebilir bir çevre yaratma amacıyla konulan hedefe ulaşmak için etkin bir araç olarak değerlendirilmiş, proje alanlarına olumlu geri dönüşler sağlamıştır. Aynı zamanda yenilikçi, inovatif, teknolojiye dayalı fikir, proje ve uygulamalar oluşturulmasına katkı sağlamıştır. Bir çevrenin minimum zarar ve maksimum fayda ile oluşturulması bağlamında son derece etkin bir sistem olduğu söylenebilmektedir. Çok farklı fonksiyonlara hizmet eden peyzaj alanlarının kendine özgü nitelikleri olmasına rağmen, planlama ve tasarımın ortak bir eksende yapılmasını sağlamakta, aynı zamanda sağlıklı bir ekosistem içinde yer almasını teşvik etmektedir. Sertifika derecesi ne olursa olsun, alan içinde bu yol haritası ile alınan kararların alana ve bütününde çevresine pozitif yönlü bir getirisi olduğu görülmektedir.

\section{SONUÇ}

Sürdürülebilir bir planlama için çevrede payı olan tüm kişi ve kuruluşlara önemli görevler düşmektedir. Bir alanın nasıl planlanacağı, nasıl tasarlanacağı, nasıl geliştirilebileceği, nasıl daha sürdürülebilir hale getirilebileceği önemlidir. 
Bu konular önemli olduğu gibi, çevreyi geliştirirken mevcut doğal çevreye de zararı en aza indirgemek gerekmektedir. $\mathrm{Bu}$ amaçla ortaya çıkan araçlardan biride sertifikasyon sistemleridir.

Gelişmiş ülkeler tarafından yakın bir geçmişte geliştirilerek uygulamaya konan bu değerlendirme sistemleri sadece yapısal unsurların çevresel performanslarını artırmakla kalmamakta, yapıyla beraber çevresinin de performansı konusunu gözden geçirmektedir. Bu sayede bu sistemler çevresel değerlendirmenin ötesinde ekonomik ve sosyokültürel konuları da ele alan, sürdürülebilirliği değerlendiren araçlara dönüşmüştür. Çok yönlü olması, konuyu kapsamlı ve tüm bileşenleri ile ele alması alanların gelişimine olumlu biçimde yön verebilmektedir.

$\mathrm{Bu}$ sertifikasyon sistemi ile, sürdürülebilirlik, çevre dostu, yeşil tasarım gibi gündemdeki önemli konular bina ölçeğinden daha büyük ölçeklerdeki açık alanlara doğru taşınmıştır.

Mevcut sertifika sistemlerinin gelişmiş ülkelerde, ulusal ve bölgesel koşullara göre hazırlanmış olması bakımından, bu sistemlerin gelişmekte olan ülkelerde doğrudan uygulanması bazı güçlükleri de beraberinde getirebilir. Sistemin entegrasyonu, ülkeler bazında, karakteristik özellikler göz önüne alınarak yapılmalıdır. Bu sebeple, sistem kapsamında alana, çevreye, bölgeye özgü koşulların nasıl değerlendirileceği ortaya konulmalıdır.

Tasarımın bu sistem kapsamında değerlendirilmesiyle, projede yapılması beklenen değişiklikler kısa vadede yatırımcıya ek bir maliyet oluştursa da çevresel faydası değerlendirilerek, orta ve uzun vadede projeye değer katan bir hal aldığı görülecektir.

Geliştirilen "derecelendirme sistemi"nin standartları, mekân tasarımı ile bu tasarımın çevreye olan etkilerini basit ve ekonomik bir şekilde değerlendirebilmekte, aynı zamanda çevreye olumsuz etkilerini azaltabilmek için kullanılmaktadır. SITES sistemi, temel konuları kapsamlı şekilde değerlendirse de halen geliştirilmeye açıktır. Proje alanı sisteme uyarlamak için yapılan düzenlemeler, farklı ve yenilikçi fikir ve uygulamaları beraberinde getirmekte ve böylelikle inovatif tasarımların önü açılmaktadır. Bu sayede yaratıcı olmayı teşvik etmektedir.

SITES, konu başlıklarını, sürdürülebilir bir çevrede olması gereken standartlar bağlamında uygun şekilde detaylandırmaktadır. Bir peyzaj alan planlaması sürecinde, alanların kendi koşulları, ihtiyaçları ve beklentileri göz önüne alınarak, sürdürülebilirliğin ön planda olması önem arz ettiğinden, bu şekilde geliştirilen bir sistemin peyzaj alanlarına pozitif katkı sunacağı düşünülmektedir.

\section{Etik Standart ile Uyumluluk}

Çıkar Çatışması: Yazarlar herhangi bir çıkar çatışmasının olmadığını beyan eder.

Etik Kurul İzni: $\mathrm{Bu}$ çalışma için etik kurul iznine gerek olmadığını beyan ederim.

\section{Finansal Destek: Yok}

Teşekkür: Yok. 


\section{KAYNAKÇA:}

Kats, G. (2003). Green building costs and financial benefits(pp. 2-8). Boston, MA: Massachusetts technology collaborative.

PBS, G. (2008). Assessing Green Building Performance: A Post Occupancy Evaluation of 12 GSA Buildings.

Reed, R., Bilos, A., Wilkinson, S., \& Schulte, K. W. (2009). International comparison of sustainable rating tools. Journal of sustainable real estate, 1(1), 1-22.

Sev, A., \& Canbay, N. (2009). Dünya genelinde uygulanan yeşil bina değerlendirme ve sertifika sistemleri. Yap1 Dergisi Yapıda Ekoloji Eki, 329, 42-47.

SITES. (2014) Certified Projects http://www.sustainablesites.org/projects. Erişim tarihi: 15.Temmuz.2020

Sustainable Sites Initiative. (2014). SITES v2 rating system for sustainable land design and development. Sustainable Sites Initiative: Austin, TX, USA, 1-151 https://www.usgbc.org/resources/sites-rating-system-and-scorecard. Erişim tarihi: 10.Temmuz.2020

Turner, C., Frankel, M., \& Council, U. G. B. (2008). Energy performance of LEED for new construction buildings. New Buildings Institute, 4(4), 1-42.

USBGC. (2008). The Sustainable Sites Initiative. (USBGC) Aralık 22, 2011 tarihinde The Sustainable Sites Initiative: http://www.sustainablesites.org/pilot_projects/ adresinden alındı

USBGC. (2009). The Sustainable Sites Initiative Guidelines and Performance Benchmarks 2009. ASLA, Lady Bird Johnson Wildflower Center at University of Texas;United States Botanic Garden. ABD: USBGC. 